\title{
What Users Really Think: How They See and Find Serials in the Arts and Sciences
}

\section{Loanne Snavely and Katie Clark}

\begin{abstract}
New users encounter numerous stumbling blocks in their search for serials. Beginning with the index, understanding the citation, searching the online catalog for the serial record, interpreting the holdings, and finally locating the item on the shelf are all steps that must be negotiated. Each step presents a variety of problems that users bring to the reference desk. The authors suggest user-oriented solutions relating to cataloging practices, screen design, and linking local holdings to periodical databases. Increased collaboration between librarians on the front lines and those creating the records and providing the access is essential for meeting end user needs.
\end{abstract}

$\mathbf{T}$ he motivation for this article came from a colleague, a serials cataloger, who changed jobs and came to work at a reference desk, and was surprised at how much trouble users had finding serials. As a cataloger, her idea of a typical user was a much more sophisticated one than she met at the desk. As reference librarians who are on the front lines and are constantly answering very basic questions from firsttime users, we were just as surprised to find out that she was unaware of these difficulties. We were further encouraged to pursue this topic by this message from another serials cataloger: "When I was a student in cataloging class, our professor [Elizabeth R. Baughman] highly encouraged us as catalogers to serve part time on the public services desk. There we would gain insight into how people actually use the catalog records we spend so much time creating, whether the records really provide the help catalogers think they do, where exactly the records fall down on the job, etc." (Riemer 1994).

The truth is that for many library patrons, in particular undergraduates and other first-time users, finding a journal is a mysterious and often frustrating process that starts long before they actually have a serial record displayed on the online catalog. These users are often familiar with small school or public libraries and are frequently accustomed to a short printed serials list. They are encountering not only a major academic library for the first time, but also a new way of finding serials. We will focus on bibliographic records for serials found through an integrated online catalog as opposed to a catalog, database, or list specifically devoted to serials.

LOANNE SNAVELY is Head, Arts Library (lls@psulias.psu.edu) and KatIE ClaRK is Head, Life Sciences Library (kec@psulias.psu.edu) at Pennsylvania State University. This report is based on a presentation made at the Association for Library Collections \& Technical Services, Serials Section, Research Libraries Discussion Group, Miami, Fla., June 1994. Manuscript received July 7, 1995; accepted for publication September 26, 1995. 
The authors have each worked at reference desks at several different libraries. Thus, the problems and situations we will discuss are not unique to libraries at institutions large or small, or private or public; nor are they unique to any one online catalog. It is our experience that at any reference desk many of the questions are about finding journals and interpreting serial records. Users must negotiate at least five steps to locate a journal: from (1) index to (2) citation to (3) serial record to (4) holdings statement to (5) shelf. The purpose of this article is to describe the stumbling blocks people encounter while negotiating these steps. Of course, not all users encounter all of the problems we describe, but each is a regular problem at the service desk.

\section{STEP 1 \\ From IndeX to Citation OR "How Do I Find ARTicles on GLobal Warming?"}

While patrons may come to the reference desk with a citation in hand, far more are in a position of looking for articles on a topic. This would normally involve looking in a periodical index, something unfamiliar to many undergraduates and almost all first-time users. Such users are frequently surprised to learn that they will not find periodical articles in the online catalog. They need instruction on selection of an appropriate database, choice of keywords, use of Boolean logic, and so on. These problems have been dealt with fairly extensively in the bibliographic instruction and database-searching literature. Once a user has identified the appropriate index and performed a relevant search, he or she must interpret the citations received. While the citations from some periodical databases are simple and clearly marked, many are more complex and do not have labeled displays. Even for those that do, the terminology is often confusing to the nonlibrarian. For example, the journal title is often labeled "source," a term familiar to all librarians but rarely to users, particularly undergraduates.

\section{STEP 2 \\ From Citation to Online Catalog Record, or "You Mean I Have TO Do MORE?!"}

The rest of the process, from having the citation in hand to having the article in hand, has been largely overlooked in the literature. This is possibly due to its being considered mechanical, in contrast to the intellectual issues of topic definition and search strategy. Users, however, find it a complex and time-consuming process. After spending more time than they had allotted for the whole project on sorting and printing a list of citations-chosen because of the promising wording of the article titles-they are stunned that they now have to go to another database. Often this means use of another terminal and looking each citation up again to see first whether the journal is owned and then to find its location. The idea that the library does not own every title indexed astonishes many new users. Like hiking at high altitudes, it gets harder rather than easier the further you go.

\section{Which TITLE DO I TYPE IN?}

Getting from the database printout to the serial record in the online catalog is not intuitive, understandable, or easy for firsttime users. This very first step, figuring out what to type into the online catalog, is a big stumbling block. Unfortunately, many users will come dragging to the desk after lengthy searching, very discouraged because they cannot find a single article. Why? Because they have been diligently typing in the title or author of the article, rather than the title of the journal.

Once a user is shown where to find the journal title on the screen or printout, it is often abbreviated, and abbreviations normally cannot be searched in an online catalog. Users are seldom aware of the availability of serial abbreviation books and even when they do know about them they rarely, if ever, use them. Users will often guess at the title. Entering the abbreviation or a wrong guess for the journal abbreviation into the online catalog can mean the difference between finding the 
journal (or at least finding the record) and going away thinking the library does not own the journal. For example, a user might reasonably guess that the title abbreviated J Am Soc Hort Sci is Journal of the American Society of Horticulture Science, but it is not. The correct title is Journal of the American Society for Horticulture Science. In a large research library, there are so many entries that start with "Journal of the American Society," that the two would not be near enough for someone to find them when an exact title search is conducted. A single preposition can cause retrieval of a wrong record or none at all.

Other common problems include the incorrect guess that does produce a result, such as interpreting the abbreviation Am J Phys as American Journal of Physiology instead of the correct title, American Journal of Physics. In this instance users may actually get to the shelf before recognizing the mistake. Another is that some journals use a "catchy" title, containing a little trick that the user does not perceive. For a title such as Atforum, a search in some online catalogs will not retrieve the title when entered as two words rather than one, unless a second entry has been added. While this seems like a minor point, many users will not find that the library owns the journal unless both forms are searchable.

\section{STEP 3 \\ From Citation \\ To SERLal RECORD, OR “What Does This Mean?"}

Once the patron has successfully identified the journal title and translated from abbreviated to full title, the battle is over. Right? Wrong! An army of confusion confronts the unsuspecting user. For example, if we trace the steps an undergraduate goes through when looking for one of the most popular journal titles found in the Life Sciences Library, Science, it will illustrate the possible pitfalls awaiting the unsuspecting student. Because the word "science" is so common, the patron is first confronted with dozens of entries. At this screen (see figure 1) users have to be able to discern the journal Science from among monographs either entitled Science or indexed with Science as a related-title added entry. Various online catalogs handle this differently, but in every case the index screen produces an overwhelming number of confusing entries.

In a NOTIS catalog, the user must first recognize the word "serial," a term that is often unfamiliar to new users, as the term

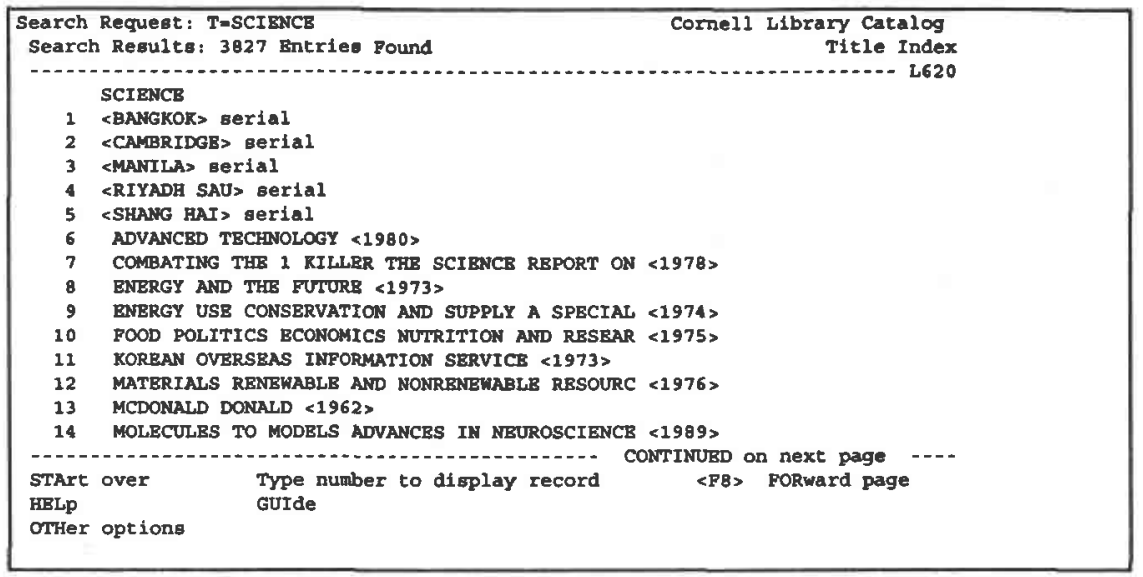

Figure 1. NOTIS Entry display for title Science 


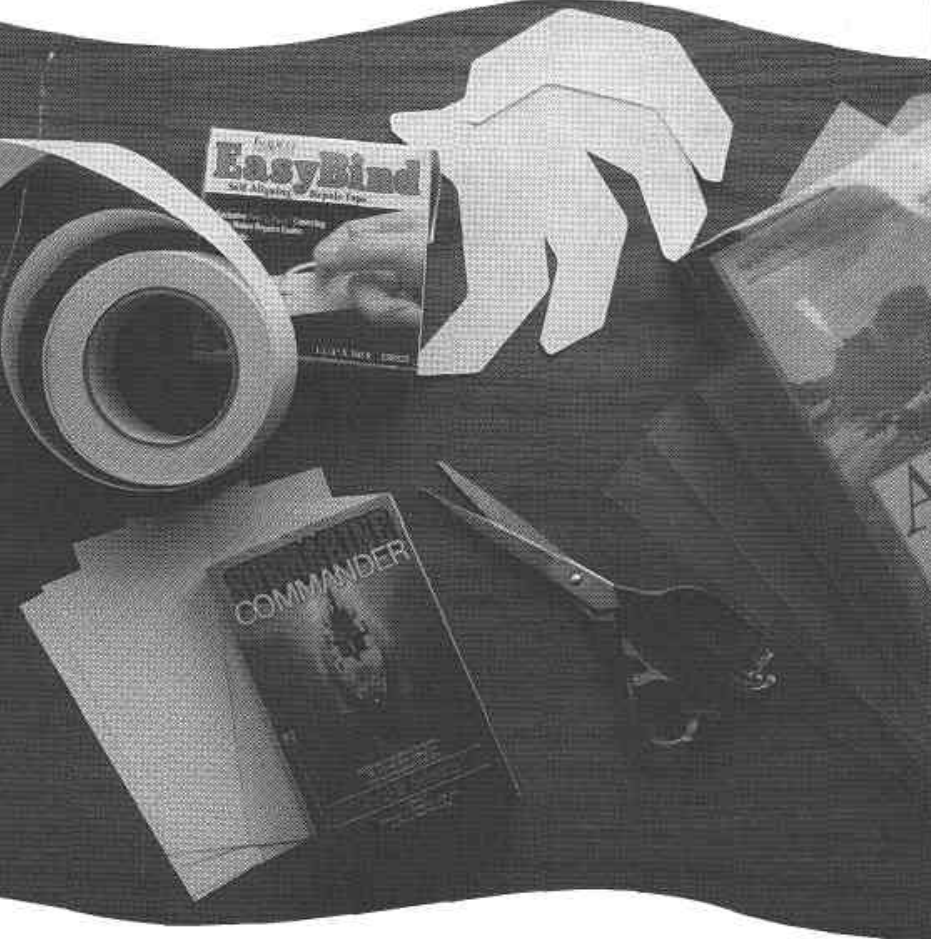

INVESTIGATE THESE

OUTSTANDING EXAMPI.ES

OF KAPCO

INGENIOUS GLUTINOSITY

\section{Easy Cover: \\ Self-Adhesive Book Covers}

Kapro Book Jacket Covens

Easy Bind

Polvester Repair Tape

\section{Easy Wings}

Spine Protection Sections

\section{Poly Cover}

Budget Prised Book Covers

Kapro Book Jacket Tape

Easy Bind II

Polyester Repair Tape

Easy Bind

bling and premature sticking. The Peel 'n Place ${ }^{\oplus}$ strip makes light work of repairs; a Kapco exclusive.

\section{ON-THE-SPOT}

TRAINING

Most Kapco products are simple to use, but all come with complete step-by-step instructions on the package. For more details, Kapco will furnish video cassette instructions. Or, a nearby Kapco field sales representative will be glad to come by and show you.

\section{SHOP BY MAIL}

\section{OR PHONE}

Too numerous to show here, all Kapco products are

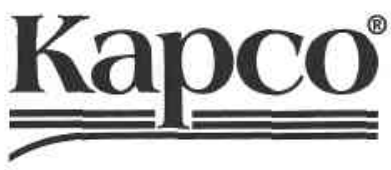

LIBRARY PRODUCTS presented in full detail with descriptions, prices and ordering procedures in our brand new Kapco library products catalog

You now may order any quantities from the catalog by mail, over the telephone with one of our courteous customer service representatives or instantly by fax.

\section{BUY DIRECT} AND SAVE Kapco is a manufacturer, not a warehouser or jobber. We sell directly to you at best possible prices. Call us today and save. by mail, phone or fax
Request a catalog or ask a customer service representative about one of our unique Kapco library products starter kits. They're money in the bank (or in the stacks, if you prefer).

CALL TOLL FREE 1-800-791-8965

FAX: 1-800-451-3724 LOCAL: 216-678-1626
Tyok Repair Tape

Kapco

Polyester Repair Corners

Easy Lam

Laminating Film

Kapco

Label Protectors

Easy Guard

Magazine Covers

Easy Guard" Plus

Extra Sirength Covers:

Easy Hold

Magazine and Pamphlet Reinforcements

KapBond

Book Repair Glue

Oillilo

Solvent/Degreaser

Easy Trim Trimmer

Kapeo

Rotary Drue Trimmer

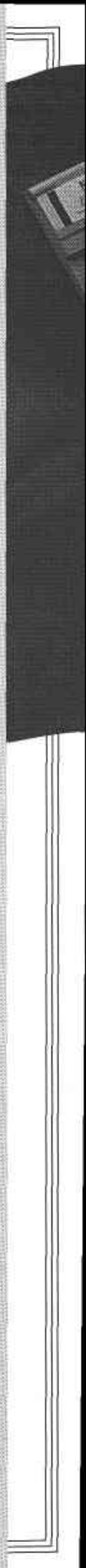




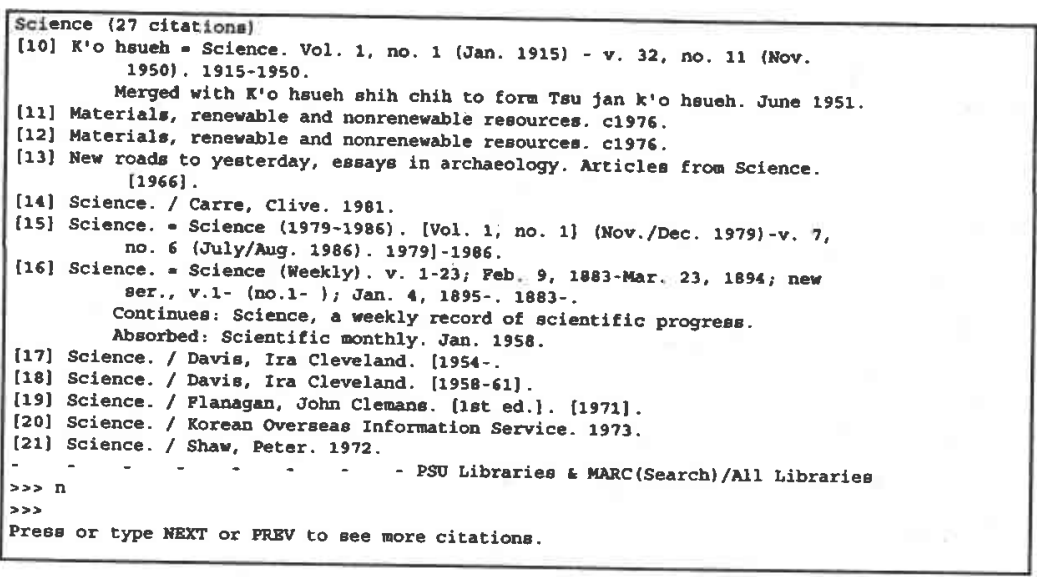

Figure 2. Citation display for title Science

that identifies the record they are looking for. They must then know the publisher's location to select the correct entry. This can be especially difficult for a title like Science, which has changed place of publication several times. In the screen shown in figure 1, the user must select the second entry even though Science has not been published in Cambridge for over a century. In an online catalog where the index screen distinguishes entries by date, the user must distinguish a serial by the punctuation after the date (see figure 2). The monograph citations, of course, end in a date-period and serial records end in a date-dash period. The difference comes down to a single character of punctuation. This is extremely difficult to see on an online catalog screen filled with text. A further problem is that, when scanning the entries, many users will see Science in the list and, noting the date 1883, will assume that is not the entry they want to choose because they are looking for a 1994 article. Thus, patrons who identify the title and perform the search correctly may still not find the entry sought.

When they have finally gone from the index screen to the individual record screen, new problems arise. Users are far more accustomed to the information given on a monographic record screen than a serials screen. Not only is the information in serials records different, it is lengthier and more complex. The more information included in the record, such as the three places of publication for Science, name changes, and mergers, the longer it is and the more difficulty people have in finding the specific piece of information they need. Thus, screen design may be more important for serials records than for any other type of material in the online catalog. Research on screen design has resulted in a 30 percent rule. "This rule says that no more than 30 percent of the screen should be filled with characters; in other words, the density of information should be 30 percent or less. The ideal, supposedly, is 15 percent. Effective displays are open displays, with lots of empty space used to clarify the important information" (Crawford 1992, 68). The brief record used in NOTIS catalogs, with the option to view more detailed information, constitutes one effective solution to this problem.

\section{STEP 4 \\ Holdings Information, or "Do You Have This Article OR NOT?!}

At last the poor, exhausted user arrives at the correct bibliographic record. The next step is to determine whether the library owns the issue sought. We know our user is looking for the holdings information, 
but does the user? The term "holdings" may be meaningless as an indication of ownership. In addition it may not be apparent where to look for that information. For very long records the novice cannot distinguish the critical information, specifically the holdings information, from the unneeded information.

When the records are very long, the holdings information can be many screens removed from the first screen of the record. Some libraries have solved this problem by using a brief record display, which has the advantage of giving the most pertinent information on the first screen. However, many of these online catalogs, such as NOTIS, require the user to take a second step and consult an additional screen for holdings information, no matter how short the bibliographic record is. The ideal from the patron's point of view would be a brief citation plus a brief holdings statement on the first screen, with more detailed information available on request.

Interpreting the publication date versus the holdings dates is a common problem. In catalogs with summary holdings displays, patrons often do not understand that only the starting date is indicated and that the open date or dash indicates that all issues since that initial date have been received. For example, users looking at a record will assume that the library only owns the first volume and nothing else.

The second frequent misinterpretation occurs when the publication date and holdings date differ. For example, at Penn State the entry for The Journal of Biological Physics shows publication date 1973at the top of the screen (see figure 3). The user assumes that the library owns everything since that date, even though the holdings statement at the bottom of the screen indicates that only issues from 1989 to date are owned. Users cannot imagine why a library would put 1973 on the top of this record when they do not own 1973-1989. Many consider it tantamount to false advertising. They are offended that the library is making it look like they have the early issues when they do not. This problem is compounded when the bibliographic record is separated from the holdings information by one or more screens.

Many, if not most, libraries use the phrase "current issues" to describe their unbound holdings. However, very few undergraduates know the library's definition of this phrase. Such terminology is commonly misinterpreted in two different ways. Some think "current issue" means the most recent issue. Others, who have been told in class to locate "current information," think "current issues" means the past five years or so.

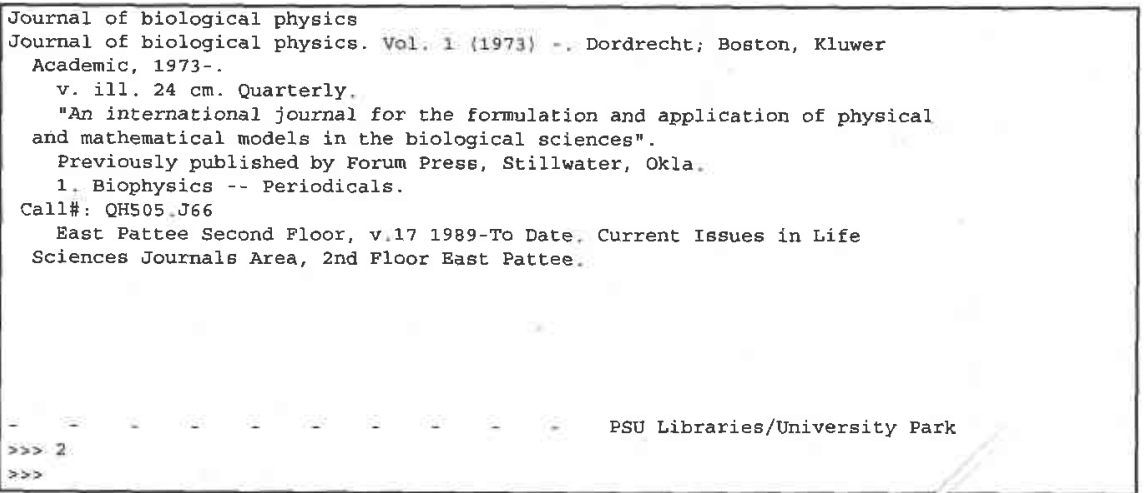

Figure 3. Record screen for Journal of Biological Physics 
Patrons are surprised to find that what a library considers a current issue could be anything from the most recent issue to one that is several years old, and what falls into this category varies from title to title. Because what remains unbound varies with the length of the issues and the frequency of the publication, current issues vary enormously. Thus, it is understandable that few users know what is meant by an unbound journal without an explanation. Ideally the catalog should provide information for each title on which issues are considered "current."

\section{STEP 5 \\ THE SHELF, OR "WHERE Do I Loox Now?"}

Because the current issues, bound issues, or a certain range of years are often shelved in different locations, it is essential that the online catalog make it clear where a patron is to go for the issue sought. An examination of online catalogs shows that many do not provide information on exactly which volumes are shelved where. Therefore, the patron frequently is in the frustrating position of having arrived at the given location only to find the desired issue is elsewhere. In some libraries all issues are either arranged alphabetically by title or by call number, while in others the current issues may be arranged alphabetically by title and the bound volumes classified by call number. The catalog records do not specify how the issues are arranged on the shelf. The call number is usually given whether or not it is needed, leaving users to figure out on their own when to search alphabetically by title or when to search by call number.

\section{Discussion OF Thornier Problems}

Above we have described problems patrons typically encounter with finding the routine journal article. Now we will enumerate some of the thornier types of problems that are familiar to serials librarians and catalogers, but that can bewilder even experienced users. A sampling of these problems are discussed below.

\section{Corporate Body and MaIN} ENTRY PROBLEMS

The concept of corporate body entry is foreign and difficult for most patrons. Novice users typically expect entry to be under "author," and think of an author as a person who has written a novel, short story, or poem-identification of authors is rarely emphasized beyond literature classes in high school. The idea of an author being a corporation or association is out of their realm of experience and therefore difficult to include in their framework of authorship.

Add to this the difficulty of identifying the title of many corporate publications such as "report," "bulletin," or "miscellaneous publication," which appear to the user to be categories or types of publication rather than titles. This is further compounded by the way these serials are cited in the literature. In addition to confusing abbreviations such as " $\mathrm{mp}$ " for miscellaneous publications, the wording of the serial title in the citation may appear to be completely different from the main entry and title in the catalog record.

Benson (1990) has outlined a discussion of the extensive problems users once had in determining main entry for serials. Fortunately, with the advent of the online catalog, knowledge of the exact main entry is not critical to locate a title. Keyword and Boolean searching have aided users immensely by eliminating the need to understand the cataloging rules. However, the problem remains that, when a user finds a citation in the Art Index to Record of the Art Museum (Princeton University), they will not find the entry using a title search if the journal was cataloged before the implementation of the Anglo-American Cataloguing Rules, 2 d ed. (AACR2 1978) and the title entry is "Record" and the main entry is "Princeton University. Art Museum," We expect patrons to realize that the library may still own this serial even though a title search produces no results. A patron who goes on to perform a keyword and Boolean search, such as "record and princeton," will locate the title. We know, however, that patrons often 
give up when a title search produces no results.

Two problems arise with this example. The first is pre-AACR2 cataloging that has not been changed and continues to present problems for users. The second is that a simple added entry for forms of titles used in citations, especially major indexing sources, would go a long way towards helping the user and making collections more accessible. Because catalogers work with the item in hand, this additional information gleaned from citation sources and users has to come from outside the cataloging source.

Another main entry problem that confuses users is the standard practice of foreign-language uniform title headings for journals published in English cover-tocover translations. Of course, users cannot understand why there is a foreign language spine title and catalog record when the publication is in English! An English main entry with a foreign-language title added entry in the record would be more useful from the patron's point of view. Libraries could also opt for a little-used MARC tag (765 Original Language Entry), so that the foreign title displays in a note as: "Translation of ...."

\section{MONOGRAPHS vS. SERIES VS. PERIODICAL}

Publications issued in multiple, nonidentical formats cause multiple problems. For example, Architectural Design is published first as a periodical, with most of the issue consisting of a numbered profile series called Architectural Design Profile. Each number contains articles on a particular topic and has a distinctive title. Each profile is also issued separately as a monograph, without the introductory material from the periodical issue. Every serials cataloger can see the problems presented in such a publication. The problems are compounded from a user's point of view because he or she may variously find: (1) a citation to an article in the profile through an index, such as Art Index or Avery Index to Architectural Periodicals, or to the periodical Architectural Design, with a volume, issue, and date; (2) a citation in the literature that refers only to Architectural Design Profile; or (3) a reference to an apparent chapter or essay in a book with the title Free Space Architecture.

Serials catalogers are discouraged, by workload-induced expediency, institutional policy, or other considerations, from providing access through the catalog for all three of these potential searches. Either the items are cataloged separately, so that individual titles may be found, or they are entered under the serial title, but normally not both. A series tracing is normally available for the Profile whether the material is cataloged as a monograph or a serial. Thus, only two out of the three search avenues are covered in the catalog.

In such situations we are dependent upon staff who are alert to the problem and can direct patrons to the article they seek when asked. But how many patrons who feel competent using the catalog, and are confident they have determined the library does not own it would go to the trouble of confirming this with library staff? The end result is that patrons may erroneously conclude the library does not own materials that it does.

\section{Publisher Bloopers}

Local decisions on how to resolve changes made by publishers should take into account how the material is indexed, and therefore how the user is likely to be searching for it. Different users may be served better by different resolutions, so the librarian may be faced with a decision that must take into account convenience, logic, library policy, and different groups of users.

A good example of such a maddening situation is the case of American Choral Review and The Voice of Chorus America, two publications of the American Choral Foundation. Or, they were two separate publications until the foundation decided, perhaps to save postage, to issue them together. Had the two titles been combined into one, the solution would be evident; or, if the two titles were just mailed together there would be no problem. Instead, the American Choral Review was inserted and stapled inside The Voice of 
Chorus America. The obvious solution is for libraries to detach the inner volume (the cover says "pull out to separate") and continue to bind each separately, and patrons are none the wiser that there has been a change. However, two complicating factors must be taken into account. The first is that the foundation has begun printing on the cover of The Voice of Chorus America not only its own title, volume, number and date, but also American Choral Review, with its volume and number. They have also added the subtitle "Incorporating the publication of the American Choral Foundation," leading the new user to expect to find in that issue both titles. The second factor is that the main indexing source, Music Index, cites articles as if the two were together. For example, if we are looking for an article by Chris White, we find the entry:

Christ lag in Todesbanden: a setting by Handel. C.D. White. mus VOICE CHORUS AM 16:ACR1-2 n3 1993

Clearly the new user will interpret this citation to mean they should search for Voice of Chorus America. So while the initial response to the foundation's decision to staple one publication inside the other may have been to separate them and maintain the status quo, an examination of the ways users are likely to find them indicates that keeping them together is now preferable. Long-term users may be inconvenienced initially, but can be alerted to the change.

\section{Finding Title Changes from the USER'S POINT OF VIEW}

The serials literature is full of debate over which method is preferable for serials that have changed title--successive, first, or latest entry. Each has its advantages and disadvantages from the user's point of view. Successive entry requires the user to search separately for each version of the title. Each of these individual records may be shorter than latest entry records would be, a distinct advantage from the user's point of view. However, users must search each title-often three, four, or morefor complete retrieval. In addition they have to interpret the often confusing terminology used to connect the varying ti- tles, such as "continues," "continued by," or "absorbed by."

Earliest entry cataloging may be easier for the serials cataloger but is probably the most confusing for the user, because the title at the top of the record retrieved will seldom be the one he or she sought. That title may be buried deep in a note, which can be hard to pick out of a screen full of text. A title such as Metals Technology, which began as Journal/Institute of Metals became Metals Technology and merged with Metal Science to form Materials Sciences and Technology. MST is a nightmare for the user no matter how it is cataloged. Whether single or successive entry cataloging provides clearest access to serial records from the patron's point of view is an issue that needs to be examined through empirical research.

\section{Conclusions and Directions FOR Future Research}

We have pointed out many problems that could benefit from further research on user needs in locating journal articles. Reference librarians get a sense of the questions frequently asked, as well as the more occasional thorny problem. However, we have no idea how many more users are smoothly finding things themselves, leaving empty-handed, giving up in frustration, or assuming the library does not own something that it actually does.

Interlibrary loan may be a source of data on the frequency with which items are requested that in fact are owned. However, these figures are far from complete because not all patrons have access to interlibrary loan, and those who do, frequently do not have the time or motivation to pursue that avenue. In addition, we have not examined empirically what effect cataloging rules have on the user's successful retrieval. Thus, while we are able to identify the types of problems encountered, we do not know what percentage of users experience these problems, or how frequently they experience them. We also do not know how often links in serial citation databases, from "source" fields to serial bibliographic records in catalogs, via ISSNs common to both, 
correctly take users to the records they need.

Studies such as Wildemuth and O'Neill (1995) begin to explore ways of incorporating user-oriented perspectives into online catalogs. However, studies with a much narrower focus will be needed to explore the complex nature of serial retrieval.

Many undergraduates come to the library with very little understanding of the research process, in particular finding and using the journal literature. They are frankly overwhelmed by the complexity of large systems. Even in the best of all possible worlds it is a difficult, time-consuming, complex process. The user must go through a minimum of five steps for each serial, any one of which may result in a problem. While further research will help identify specific problem areas, we see three areas where changes can be made now to help users.

The first is to link holdings from periodical databases to serial holding records. Examples are the multi-database access system (MDAS) product from NOTIS and other in-house efforts such as Penn State Libraries' Table of Contents (TOC) database. In these cases database citations are linked directly to serial records. This eliminates the need for the user to identify the title and search the online catalog properly but still does not resolve the holdings and locations issues. Ideally, patrons would like to be able to type in the volume number of the issue they need and have the system respond with the exact location and shelving arrangement.

The second area is screen design and record information such as holdings that may be influenced by vendor decisions on online catalog design as well as local policy. Wallace (1993, 249) recommends that "successful screen designs and search engines should focus first and foremost on meeting the quick-searching needs of the majority of users." A short record that is clear and easy to understand meets the needs of most users. Extensive notes and other information needed for clarification should be available at the user's request.
In addition, careful attention must be given to wording used. The meaning of words such as source, citation, holdings, current issues, continuing, series, serial, periodical, and index may not be clear to the user.

The third area where changes could be useful are cataloging rules and practices. Rule-making bodies must take user needs into consideration (these are really library needs, too). Because the decisions made about how titles will be cataloged, how holdings will be displayed, and so on have enormous, long-term implications for users, we need to work together on solutions.

We, the entire library profession, need to refocus our attention on the users. How do they look for serials? How do they interpret information on the screen? For example, simple title-added entries for commonly cited forms of the titles, including abbreviations, would solve many users' and public service librarians' headaches. While rules may allow for adding these entries, local policies and communication barriers may often prevent them. Also, English main entries and titles should be used for English translations of serials originally published in another language. Complicated titles, such as Architectural Design, require innovative solutions to ensure that the user can find the title from all possible citation formats. When patrons cannot find something the library owns because there is no entry for it in the catalog, the library has failed them. In an era of declining budgets, it is ever more critical that material the library owns can be located by library users. In cases where the rules do not serve the best interest of the users, the rules should be changed. In cases where local policy is the issue, those policies should be given reconsideration in light of user needs.

We have come a long way in addressing user needs, but a review of problems indicates that there are still many areas where we could improve. Meeting customer service needs will provide us with a challenge in the decade to come. If libraries are to compete in the information age, they must take the lead in meeting this challenge. 


\section{Works Cited}

Benson, Larry D. 1990. The serials catalog: A view from the reference desk. In Serials and reference services, ed. Robin Kinder and Bill Katz. New York: Haworth, 12339.

Crawford, Walt. 1992. Starting over: Current issues in online catalog user interface design. Information technology and libraries 11: 62-76.

Lim, Sue C. 1988. Successive entry serials cataloging: An evaluation. The serials $l_{i-}$ brarian 14, nos. 1/2: 5, 59-69.
Riemer, John. 1994. E-mail to the authors, 24 August.

Wallace, Patricia M. 1993. How do patrons search the online catalog when no one's looking? Transaction log analysis and implications for bibliographic instruction and system design. $R Q$ 33: 239-52.

Wildemuth, Barbara M., and Ann L. O'Neill. 1995. The "known" in known-item searches: Empirical support for user-centered design. College \& research libraries 56: 265-81. 